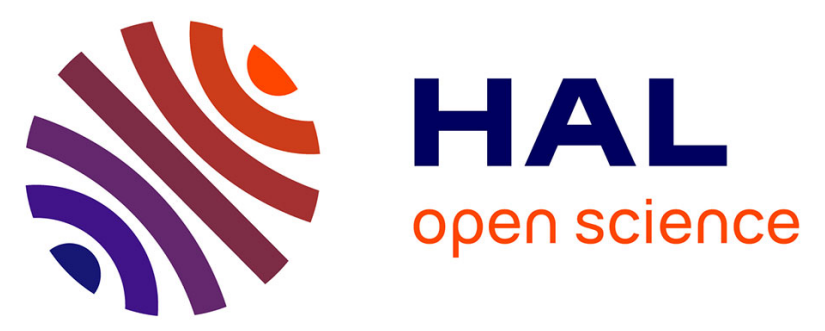

\title{
The Opposite Effects of the Heating Rate on the TSL Sensitivity of Ge doped Fiber and TLD500 Dosimeters
}

Mourad Benabdesselam, Franck Mady, Jean Bernard Duchez, Yasmine Mebrouk, Sylvain Girard

\section{- To cite this version:}

Mourad Benabdesselam, Franck Mady, Jean Bernard Duchez, Yasmine Mebrouk, Sylvain Girard. The Opposite Effects of the Heating Rate on the TSL Sensitivity of Ge doped Fiber and TLD500 Dosimeters. IEEE - Nuclear and Space Radiation Effects on Components NSREC 2014, Jul 2014, Paris, France. 10.1109/TNS.2014.2354512 . hal-01307780

\section{HAL Id: hal-01307780 \\ https://hal.science/hal-01307780}

Submitted on 27 Apr 2016

HAL is a multi-disciplinary open access archive for the deposit and dissemination of scientific research documents, whether they are published or not. The documents may come from teaching and research institutions in France or abroad, or from public or private research centers.
L'archive ouverte pluridisciplinaire HAL, est destinée au dépôt et à la diffusion de documents scientifiques de niveau recherche, publiés ou non, émanant des établissements d'enseignement et de recherche français ou étrangers, des laboratoires publics ou privés. 


\title{
The Opposite Effects of the Heating Rate on the TSL Sensitivity of Ge- doped Fiber and TLD500 Dosimeters
}

\author{
M. Benabdesselam, Member, IEEE, F. Mady, Member, IEEE, J.B. Duchez, Student Member, IEEE, Y. \\ Mebrouk, Student Member, IEEE, S. Girard, Senior Member, IEEE
}

\begin{abstract}
One of the main criteria for choosing a thermoluminescent dosimeter (TLD) is its sensitivity to the radiations under investigation. Increasing the heating rate during readout appears often necessary to reduce the time between the measurements and the dose evaluation, especially in routine dosimetry. However, doing this degrades the radiation sensitivity of the common dosimeters, as illustrated in this work for the TLD500 dosimeter. It is shown that the germanium-doped optical fiber is not only more sensitive to radiation than these COTS dosimeters but, unlike them, its sensitivity is enhanced when the heating rate increases. The physical origin of this rare effect of sensitivity enhancement is probably due to the temperature dependence of the recombination rate by which the detrapped electrons upon stimulation are transferred to the luminescent centers.
\end{abstract}

Index Terms - Dosimeters, Dosimetry, X-rays, Germanium, Irradiation, Optical fiber, Radiation therapy, Thermoluminescence.

\section{INTRODUCTION}

In the last decades, the photon irradiation response of optical fibers has been investigated [1,2] and more recently a large body of work was done on the thermoluminescence response of silica based optical fibers for application as radiation dosimeters in radiotherapy [3].

Thermoluminescence or thermally stimulated luminescence (TSL) is the property of some previously irradiated wide band gap materials to emit light or radiation as they are heated. The thermal energy supplied during heating causes carriers to move from filled traps to recombine with luminescence centers. When the recombination is radiative, photons are emitted and a TSL signal is obtained. The light emitted is a

M. Benabdesselam, F. Mady, J.B. Duchez and Y. Mebrouk are with the Université Nice Sophia Antipolis, CNRS, Laboratoire Physique de la Matière Condensée, UMR 7336, F-06108, Nice cedex 2 France (e-mail: ben@unice.fr, Franck.Mady@unice.fr, jbduchez@unice.fr, Yasmine.Mebrouk@unice.fr).

S. Girard is with the Laboratoire Hubert Curien, UMR CNRS 5516 -

Université de Saint-Etienne, 18, rue du Pr. Benoit Lauras, F-42000 Saint-

Etienne, France (email: sylvain.girard@univ-st-etienne.fr). result of the drop in energy level that occurs as the carriers move from traps to luminescent centers. This phenomenon is deeply studied and explained $[4,5]$.

Like many authors [6-8], we have recently demonstrated the ability of the Germanium (Ge) doped silica-based optical fiber (GDF) to meet all the main criteria required by a TL dosimeter (TLD) and thus be attractive in TSL dosimetry $[9,10]$. In addition, these results showed that this potentially cheap material whose TSL response is independent of dose rate over 14 decades [11], is sensitive to $\gamma$, neutrons and protons. All these features make GDF suitable for the dosimetry associated with radiation test facilities, such as those providing low energy protons for SEE measurements [10].

All these properties have been demonstrated in the case of a heating rate $\beta=1 \mathrm{~K} \mathrm{~s}^{-1}$. We focus our attention on a particular property that relates to the efficiency of luminescence through the TSL response based on the increase in heating rate. Indeed, to save time in routine dosimetry, the physicists conduct dosimeter readings at higher heating rates $\left(15 \mathrm{~K} \mathrm{~s}^{-1}\right)$.

Sensitivity is an important criterion in the choice of a dosimeter but for the most commonly used commercial TLDs, this sensitivity is strongly reduced as the heating rate increases. In other words, the advantage of high sensitivity of these TLDs is lost at high heating rates readings $[12,13]$.

The aim of this work is to show how, in contrast, the TSL sensitivity of GDF rather tends to increase with the heating rate by comparing some TSL features of GDF and those of one commonly used TLD.

\section{EXPERIMENTAL DETAILS}

Prior to measurement, the polymer cladding of the fiber is removed over a length of $3 \mathrm{~m}$. The obtained bare fiber is cleaned and cut in small pieces of few millimeters in length and then put on a $10 \mathrm{~mm}$ diameter aluminum pellet. The amount of fiber in the pellet is $49 \mathrm{mg}$.

Irradiations were achieved in air at room temperature (RT) by means of an X-ray source (XRG3500 - Inel). The tube is composed by a $\mathrm{Cu}$ target with an accelerating voltage of 45 $\mathrm{kV}$. The beam was calibrated by means of an ionization chamber connected to a high-resolution electrometer.

The comparative study was made on two samples: a Ge-doped core fiber (GDF) $(62.5 / 125 \mu \mathrm{m})$, fabricated and drawn in our lab with the same specifications as the GeD2 fiber, produced 
by iXFiber SAS. Ge content as well as the doping profiles are quite similar to those already reported $[14,15]$. The second sample is a commercially available dosimeter (TLD500), which consists of a single crystal $(\phi 5 \times 0.9 \mathrm{~mm})$ of anion defective aluminum oxide $\mathrm{Al}_{2} \mathrm{O}_{3}$ : C. Its mass is $72 \mathrm{mg}$.

For TSL readout, the samples are previously irradiated always at the same dose of $10 \mathrm{~Gy}(1 \mathrm{krad})$ and then heated linearly at different rates from RT to $700 \mathrm{~K}$. On the home made TSL reader we used, the heating rates spread from 0.1 to $8 \mathrm{~K} \mathrm{~s}^{-1}$. The emitted TSL signal was recorded by means of a UVVisible photomultiplier tube (PMT). The spectral resolution of TSL is achieved by an optical multichannel analyzer (OMA) consisting of an optical fiber connected to a spectrograph equipped with a CCD array and an appropriate grating.

\section{RESUlTS AND DISCUSSION}

\section{A. TSL features and trapping parameters}

Figure 1 is the superimposition of TSL responses obtained on both GDF and TLD500 at the same heating rate $\left(1 \mathrm{~K} \mathrm{~s}^{-1}\right)$ and after the same X-ray irradiation. A main peak, known as the dosimetric peak characterizes the glow curve of TLD500 at $438 \mathrm{~K}$. A small but less significant peak is also observed at around $590 \mathrm{~K}$. The glow curve of GDF is dominated by a broad component peaking at $533 \mathrm{~K}$. This peak broadening (FWHM of $104 \mathrm{~K}$ ) reveals the amorphous nature of the GDF material. By taking into account the mass of each sample, one can see that the intensity of the latter peak is more than for times greater than that of TLD500 dosimetric peak. It is worth noting that this sensitivity of GDF could be increased further if the Ge was also present throughout the cladding.

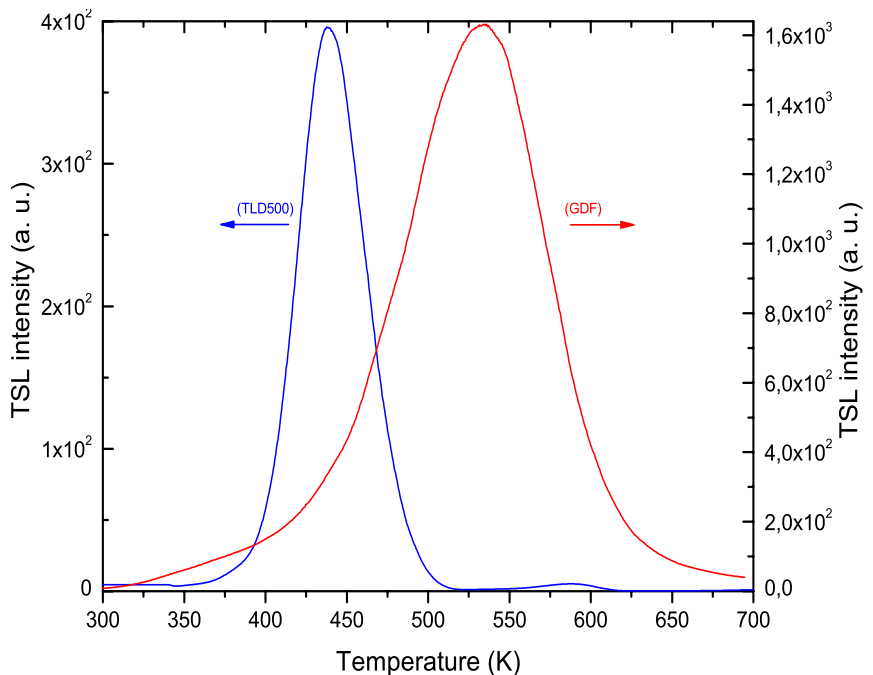

Fig. 1. Compared TSL glow curves of GDF and TLD 500 under the same conditions of irradiation (1 krad) and readout $\left(1 \mathrm{~K} \mathrm{~s}^{-1}\right)$.

The trapping parameters associated with dosimetric peak of TLD500 were evaluated using several techniques by many authors $[12,16]$. However, we have no information on the distribution of trap levels in the band gap of the silica based GDF structure. To do this, we used the initial rise method [4], as it will determine experimentally the trap depth, independently upon the kinetics order of the recombination process. By plotting $\ln I$ as a function of $(1 / T)$, where $I$ is the
TSL intensity and $T$ the temperature, straight lines are obtained on this Arrhenius plot. From the slope of these lines, activation energies of traps are determined by this method and shown in Figure 2 wherein it is seen that the trap depth associated to the TSL signal at $533 \mathrm{~K}$ on GDF is $\mathrm{E}_{\text {Trap }}=1.4 \pm$ $0.14 \mathrm{eV}$.

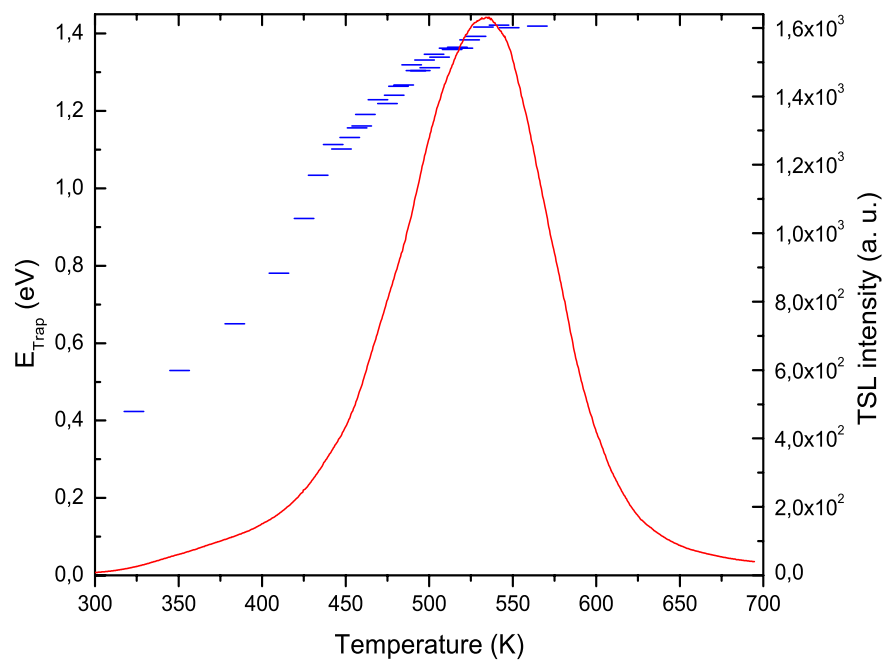

Fig. 2. Typical TSL glow curve of a Ge-doped optical fiber after X-ray irradiation at RT and the trap depth evaluated by the initial rise method.

The spectral analyses of the TSL peaks obtained on each sample are shown in Figure 3. For TLD500, two bands compose the emission: the main one at $2,9 \mathrm{eV}(428 \mathrm{~nm})$ is characteristic of the $3 \mathrm{P}-1 \mathrm{~S}$ transitions of $\mathrm{F}$ centers and the second one at $3,75 \mathrm{eV}(331 \mathrm{~nm})$ corresponding to the $1 \mathrm{~B}-1 \mathrm{~A}$ transitions in $\mathrm{F}^{+}$centers [5].

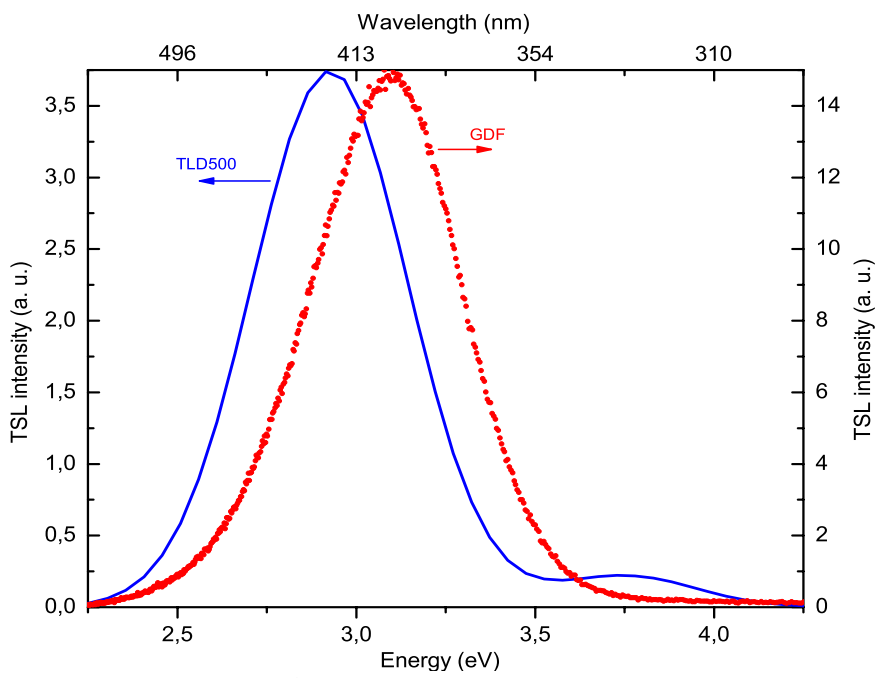

Fig. 3. Spectral analysis of the main TSL peak obtained on GDF and TLD 500 under the same conditions of irradiation and readout $\left(\beta=1 \mathrm{~K} \cdot \mathrm{s}^{-1}\right)$.

The spectrum corresponding to the TSL emission of GDF presents a single emission band around $3 \mathrm{eV}$ which is divided into two Gaussian, a main one peaking at $3.1 \mathrm{eV}(400 \mathrm{~nm})$ and a second much less intense at $2.7 \mathrm{eV}(460 \mathrm{~nm})$. The band at $2.7 \mathrm{eV}$ is the luminescence due to the T1-S0 transition associated with Si-ODC centers (II) [17] while the main band 
centered at $3.1 \mathrm{eV}$, is allocated to the twofold coordinated $\mathrm{Ge}$ centers $(=\mathrm{Ge}$ :) consisting of an electron pair located on a germanium atom bonded to two oxygen atoms. Both centers are known as electron centers [18].

We see on this figure that the main TSL emission bands of these two dosimeters were similar with a FWHM of $0.4 \mathrm{eV}$ for GDF and $\sim 0.5 \mathrm{eV}$ for TLD500 and, although of completely different origins, the maxima of these two emissions are only separated by $30 \mathrm{~nm}$. In both cases, the emission is conveniently located with respect to the photocathode spectral response of most UV-Visible PMTs used in dosimetry.

\section{B. Heating rate Effects}

We have shown in the previous section that the two samples are sensitive to radiation and are quite suitable for TSL dosimetry. Nevertheless, it is interesting to examine what becomes this sensitivity when the heating rate increases. Indeed, for use in routine dosimetry, fast readings will undoubtedly gain valuable time to dosimetrists.

Figure 4 represents the TSL response as the integral of the dosimetric peak of TLD500 obtained for heating rates varying between 0.1 and $8 \mathrm{~K} \mathrm{~s}^{-1}$. The dosimetric peak shifts towards higher temperatures and TSL sensitivity decreases by almost a factor of 4 . Some authors have reported a factor of 4,5 when the heating rate increases from 1 to $10 \mathrm{~K} \mathrm{~s}^{-1}$ [19] and even a factor of more than 16 when the heating rate increases from 0.6 to $40 \mathrm{~K} \mathrm{~s}^{-1}$ [12]. This means that the important criterion of sensitivity of the dosimeter is negatively affected when increasing the heating rate.

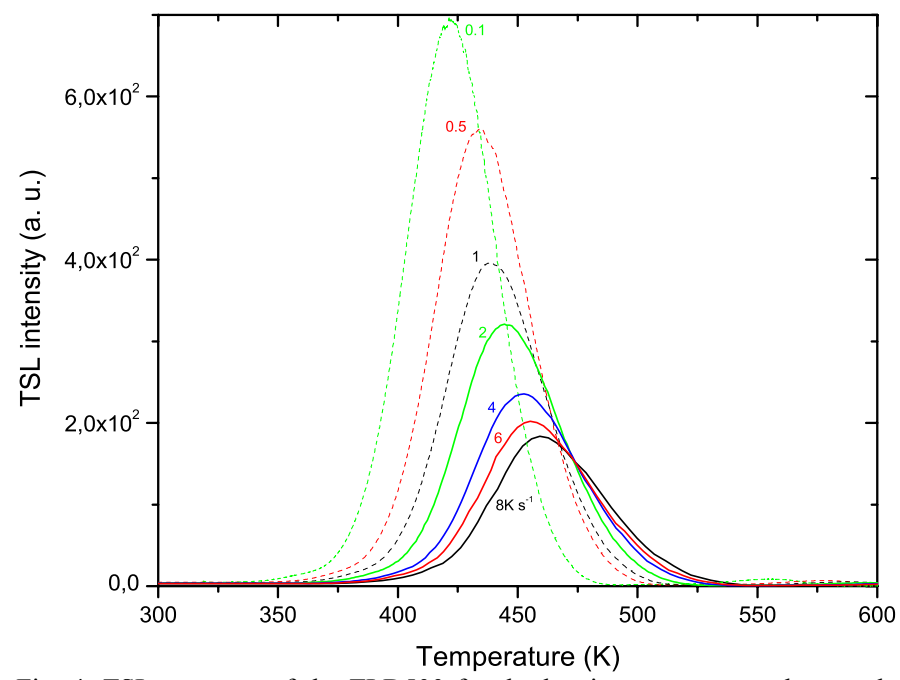

Fig. 4. TSL response of the TLD500 for the heating rates reported on each glow curve.

Under the same conditions of irradiation and readout, we report in Figure 5 the integral of the TSL peak of GDF to the same variations of the heating rate. Here also, a shift of the main peak towards higher temperatures is also observed but unlike in TLD500, the TSL sensitivity of GDF tends rather to grow about 3 times when the heating rate increases.

From a purely dosimetry point of view, this enhancement of the TSL sensitivity with $\beta$ is undoubtedly a significant asset to the fiber GDF, especially in the field of low dose levels.
In both cases (Figures 4 and 5), the behavior of the above TSL responses depending on the heating rate is not consistent with models of TSL kinetic theory [5]. Indeed, these models predict well the shift of the peak towards higher temperatures but on the other hand, for a given dose, the integral of the response should remain constant.

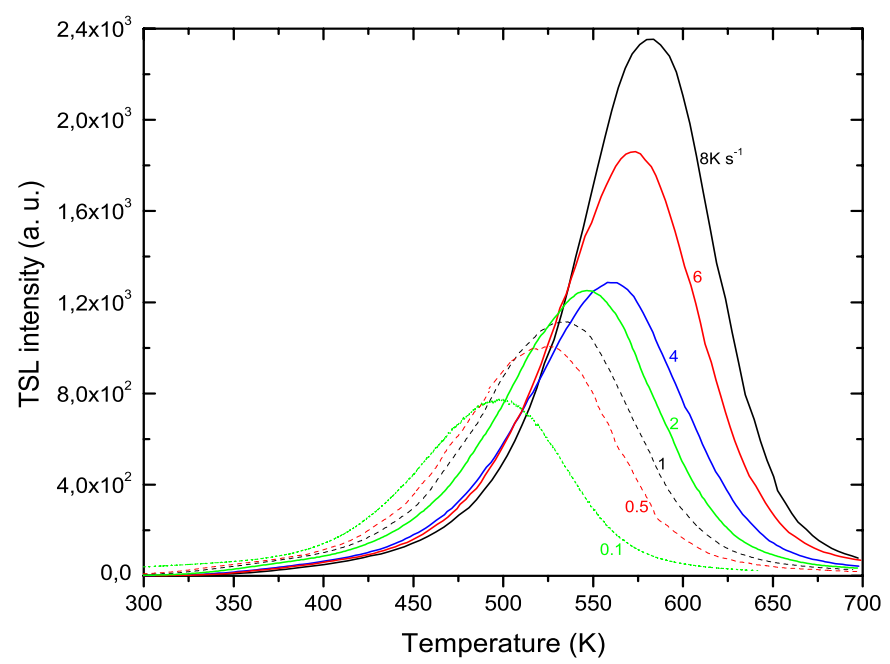

Fig. 5. TSL response of the GDF for the heating rates reported on each glow curve.

For TLD500, the temperature shift is about $38 \mathrm{~K}$ while it reaches $83 \mathrm{~K}$ in the case of GDF.

In the case of TLD500, the TSL decrease with the heating rate (Fig. 4) is very well understood and clearly identified as being due to the effect of thermal quenching of the F-center luminescence efficiency [20]. Concerning GDF, the trend is rather different and even unusual since the integral of the glow peak increases with the heating rate (Fig. 5).

Assuming that this integral is somehow the product of the TSL peak intensity times its width, we present in Fig. 6 the variation of the FWHM $\Gamma$ of the TSL peak as a function of $\beta$.

Despite substantial shift in peak temperature $(83 \mathrm{~K})$, there was no obvious relationship between FWHM and the heating rate except a variation of $\pm 4 \mathrm{~K}$ around a mean value $\Gamma_{\mathrm{m}}=100,7 \mathrm{~K}$. We can therefore consider that the increase of the integral with the heating rate is mainly due to that of the TSL intensity.

Some authors have already observed the increase of TSL as a function of the heating rate, as in $[21,22]$. They attributed this effect to the temperature dependence of the rate $S$ by which the released carriers are recombined to the luminescent centers. This temperature dependence of $S$ is deduced from the shift to higher temperatures of the whole peak when the heating rate increases as argued in [22].

We studied this assumption in the case of GDF by plotting changes in the integrated TSL as a function of the temperature at the peak maximum $\left(\mathrm{T}_{\max }\right)$ obtained for each heating rate (Fig. 7). One can see on this figure that the TSL response varies linearly with the peak maximum temperature. So if one considers that the TSL integrated area is directly proportional to the recombination rate $S$ and that this area increases linearly with $\mathrm{T}_{\max }$, one can assume that the luminescence efficiency of GDF should increase with temperature and therefore with the heating rate. This assumption is true also if one thinks in terms 
of TSL intensity since the FWHM remains almost constant with $\beta$.

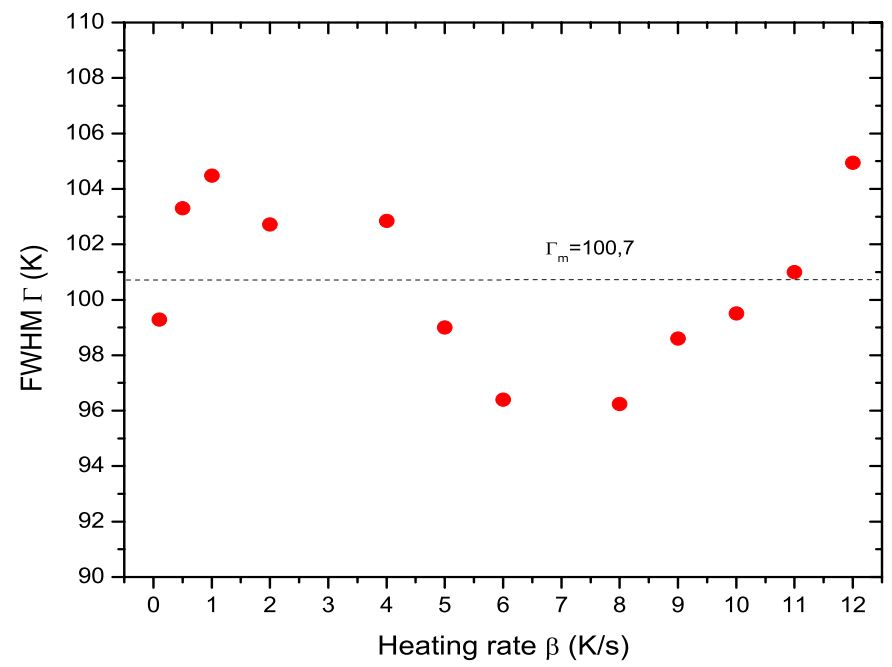

Fig. 6. The FWHM $\Gamma$ of the TSL peak of GDF at different heating rates.

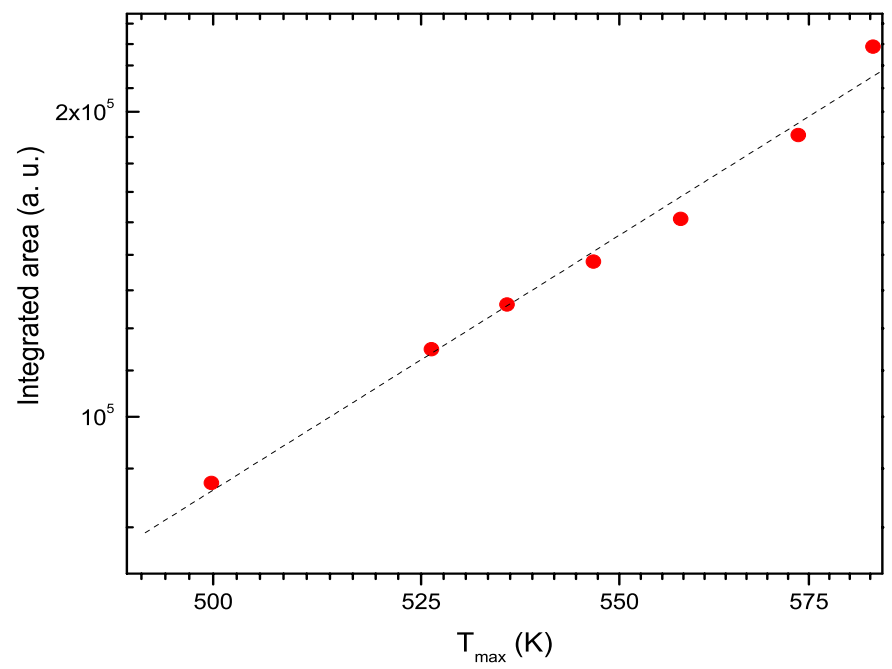

Fig. 7. Integrated area of the main TSL peak as a function of the temperature of its maximum obtained at different heating rates.

\section{CONCLUSIONS}

The extremely high and already demonstrated sensitivity of the TSL response of Ge-doped fiber is enriched with a no less important dosimetric criterion of enhanced efficiency at high reading rates. We have shown that unlike TLD500, sensitivity of the GDF fiber dosimeter increases with the heating rate, which could make it very popular with physicists by the time saved during routine use without loss of efficiency.

This rare effect of the luminescence efficiency increase with $\beta$ is believed to be due to the temperature dependence of the recombination rate of released carriers during heating.

Finally, this increasing sensitivity with the heating rate may also be an advantage when measuring very low dose levels as microdosimetry or environmental dosimetry.

Additional results related to the ability of the fiber-based dosimeter to store the dose information in the presence of light will be presented in the final paper will again confirm the attractiveness of Ge-doped optical fibers in TSL dosimetry.

\section{REFERENCES}

[1] E.J. Friebele, D.L. Griscom, and G.H. Siegel, "Defect centers in a germanium-doped silica-core optical fiber," J. Appl. Phys. vol. 45, no. 8, pp. 3424-3428, 1974.

[2] E.J. Friebele, P.C. Schattz, M.E. Gingerich, "Compositional effects on radiation response of Ge-doped silica core optical fibre waveguides", Appl. Opt. 19, pp. 547-553, 1982.

[3] M.C. Aznar, C.E. Andersen, L. Botter-Jensen, S.A.J. Back, S. Mattson, F. Kjaer-Kristoffersen, J. Medin, "Real-time optical fiber dosimetry in radiotherapy", Med. Phys. Biol. vol. 49, pp. 1655-1669, 2004.

[4] S.W.S. McKeever, Thermoluminescence of Solids, Cambridge, Solid State Science Series, Cambridge University Press U.K., 1985.

[5] R. Chen, S.W.S. McKeever, "Theory of Thermoluminescence and Related Phenomena", World Scientific Publishing, Singapore 1997.

[6] A.A. Youssef, R.P. Hugtenburg, D.A. Bradley, "Review of development of a silica-based thermoluminescence dosimeter" Radiat. Phys. Chem., vol. 74, pp. 459-481, 2005.

[7] C.L. Ong, S. Kandaiya, H.T. Kho, M.T. Chong, "Segments of a commercial Ge-doped optical fiber as a thermoluminescent dosimeter in radiotherapy", Rad. Meas., vol. 44, pp. 158-162, 2009.

[8] S. Hashim, S. Al-Ahbabi, D.A. Bradley, M. Webb, C. Jeynes, A.T. Ramli, H. Wagiran, "The thermoluminescence response of doped $\mathrm{SiO} 2$ optical fibres subjected to photon and electron irradiations », Applied Radiation and Isotopes, 67, p. 423-427, 2009.

[9] M. Benabdessselam, F. Mady, S. Girard, "Assessment of Ge-doped optical fibre as a TL-mode detector," J. Non-Cryst. Solids, vol. 360, pp. 9-12, 2013.

[10] M. Benabdesselam, F. Mady, S. Girard, Y. Mebrouk, J.B. Duchez, M. Gaillardin and P. Paillet, "Performance of Ge-Doped Optical Fiber as a Thermoluminescent Dosimeter", IEEE Trans. Nucl. Sci., vol. 60, no. 6, pp. 4251-4256, Dec. 2013.

[11] F. Mady, M. Benabdesselam, J.B. Duchez, Y. Mebrouk and S. Girard, "Global View on Dose Rate Effect in Silica-Based Fibers and Devices Damaged by Radiation-Induced Carrier Trapping", IEEE Trans. Nucl. Sci., vol. 60, no. 6, pp. 4341-4348, Dec. 2013.

[12] G. Kitis, J.G. Papadopoulos, S. Charalambous and J.W.N. Tuyn, "The influence of heating rate on the response and trapping parameters of $\alpha$ $\mathrm{Al}_{2} \mathrm{O}_{3}$ : C", Radiat. Prot. Dosim., vol. 55, no. 3, pp. 183-190 (1994).

[13] G.C. Taylor and E. Lilley, "Rapid Readout Rate Studies of Thermoluminescence in LiF (TLD100) Crystals", J. Phys. D: Appl. Phys., vol.15, pp. 2053-2065, 1982.

[14] A. Alessi, S. Girard, C. Marcandella, S. Agnello, M. Cannas, A. Boukenter, Y. Ouerdane, "X-ray irradiation effects on a multistep Gedoped silica fiber produced using different drawing conditions," J. NonCryst. Solids, vol. 357, pp. 1966-1970, 2011.

[15] S. Girard, Y. Ouerdane, G. Origlio, C. Marcandella, A. Boukenter, N. Richard, J. Baggio, P. Paillet, M. Cannas, J. Bisutti, J.P. Meunier, R. Boscaino, "Radiation effects on silica-based performs and optical fibers: experimental study with canonical samples," IEEE Trans. Nucl. Sci., vol. 55, no. 6, pp. 3473-3482, Dec. 2008.

[16] V.S. Kortov, I.I. Milman, V.I. Kirpa, and J. Lesz, "Some features of $\alpha$ $\mathrm{Al}_{2} \mathrm{O}_{3}$ dosimetric thermoluminescnt crystals", Radiat. Prot. Dosim., vol. 55, no. 4, pp. 279-283, 1994.

[17] L. Skuja, "Optical Properties of Silica" in Defects in $\mathrm{SiO}_{2}$ and Related Dielectrics: Science and Technology, p108 Edited by G. Pacchioni, L. Skuja and D. L. Griscom, 2000.

[18] D.L. Griscom, "Trapped-electron centers in pure and doped glassy silica: A review and synthesis", J. Non-Cryst. Solids, vol. 357, pp. 1945-1962, 2011.

[19] S.W.S. McKeever, M. Moscovitch, P.D. Townsend, "Thermoluminescence Dosimetry Materials: Properties and Uses", Nuclear Technology Publishing, ISBN 187096519 1, 1995.

[20] M.S. Akselrod, N. Agersnap Larsen, V. Whitley and S.W.S. McKeever, "Thermal quenching of F-center luminescence in $\mathrm{Al}_{2} \mathrm{O}_{3}: \mathrm{C}$ ", J. Appl. Phys. vol. 84, no. 6, pp. 3364-3373, 1998.

[21] A.J.J. Bos, "On the energy conversion in thermoluminescence dosimetry materials", Rad. Meas., vol. 33, no. 5, pp. 737-744, 2001.

[22] G. Kitis, G.S. Polymeris, V. Pagonis and N.C. Tsirliganis, "Thermoluminescence response and apparent anomalous fading factor of Durango fluorapatite as a function of the heating rate", phys. stat. sol. (a), vol. 203, no. 15, pp. 3816-3823, 2006. 